\title{
ANÁLISE DO POTENCIAL DE FLEXIBILIDADE ESTRUTURAL: O CASO DE UMA COOPERATIVA DE TRABALHO
}

\section{ANALYSIS OF STRUCTURAL FLEXIBILITY POTENTIAL: THE CASE OF A COOPERATIVE}

\author{
Data de submissão: 02/09/2013 \\ Aceite: $19 / 07 / 2014$ \\ Dyogo Felype Neis ${ }^{1}$ \\ Marison Luiz Soares ${ }^{2}$ \\ Mauricio Fernandes Pereira ${ }^{3}$
}

\section{RESUMO}

Esta pesquisa visou analisar o potencial de flexibilidade estrutural de uma Cooperativa de TrabaIho Médico sob a ótica da coalizão dominante. Caracteriza-se como uma pesquisa qualitativa, com objetivo de caráter descritivo, delineada pela estratégia de pesquisa de estudo de caso único. Os dados foram coletados a partir de entrevistas semiestruturadas, pesquisa documental e observação direta sistemática. Constatou-se que o ambiente no qual a Cooperativa atua é dinâmico e complexo, sobretudo em decorrência do mercado ser regulamentado pela Agência Nacional de Saúde Suplementar e da entrada de novos concorrentes, além dos aspectos sociais, culturais e econômicos que permeiam qualquer segmento de mercado. Este contexto tende a exigir maior potencial de flexibilidade das organizações. Entretanto, mesmo atuando neste contexto e se tratando de uma cooperativa, os resultados da pesquisa indicam o predomínio de aspectos mecanicistas. A flexibilidade da estrutura está associada ao seu grau de mecanicidade: quanto mais mecânica, menos flexível. O processo de gestão cooperativista, o porte da organização e a utilização do Sistema de Gestão da Qualidade são aspectos que restringem o potencial de flexibilidade estrutural deste estudo de caso.

Palavras-chave: Cooperativismo. Potencial de flexibilidade. Estrutura organizacional.

\footnotetext{
${ }^{1}$ Possui graduação em Administração pela Faculdade Estácio de Sá de Santa Catarina, FESSC, mestrado em Administração pela Universidade Federal de Santa Catarina, UFSC e doutorado em andamento em Administração pela Universidade Federal de Santa Catarina, UFSC. Florianópolis. Santa Catarina. Brasil. E-mail: dyogoneis@hotmail.com

${ }^{2}$ Possui graduação em Administração de Empresas pela Universidade do Vale do Itajaí, UNIVALI, mestrado em Engenharia de Produção pela Universidade Federal de Santa Catarina, UFSC e doutorado em Engenharia de Produção pela Universidade Federal de Santa Catarina, UFSC. Vitória. Espírito Santo. Brasil. E-mail: marison@matrix.com.br

${ }^{3}$ Possui graduação em Administração pela Universidade Federal de Santa Catarina, UFSC, mestrado em Engenharia de Produção pela Universidade Federal de Santa Catarina, UFSC e doutorado em Engenharia de Produção pela Universidade Federal de Santa Catarina, UFSC. Florianópolis. Santa Catarina. Brasil. E-mail:mfpcris@gmail.com
} 


\begin{abstract}
The article aims to analyze the structure flexibility potential of a Medical Cooperative from the perspective of Dominant Coalition. It is characterized as a qualitative research, with the descriptive objective and delineated by the single case study strategy. The data were collected through semi-structured interviews, document analysis and systematic direct observation. It was found that the environment that the Cooperative operates is dynamic and complex, mainly due to the market being regulated by Government, the entry of new competitors, as well as social, cultural and economic factors that underlie any market. This context tends to require greater flexibility potential of organizations. The structural flexibility is associated with the degree of mechanistic: the more mechanical, less flexible. However, even acting in this context and being set up as a cooperative, research indicates the predominance of mechanistic aspects. The cooperative management model, the size of the organization and the use of the Total Quality Management, are aspects that restrict the potential for structural flexibility of Cooperative.

Keywords: Cooperative. Flexibility potential. Organizational structure.
\end{abstract}

\title{
1 INTRODUÇÃO
}

As organizações têm passado por significativas transformações em seu comportamento. Ao contrário da administração clássica, que considera as organizações como um sistema fechado, a teoria organizacional contemporânea assume uma perspectiva mais dinâmica, na qual as organizações são vistas como sistemas abertos. Assim, é imperioso o poder da flexibilização na busca de constante adaptação estratégica (SOARES; TEIXEIRA; PELISSARI, 2011). O mercado globalizado, a necessidade de crescimento e a facilidade de acesso à informação tornam o cenário mais complexo e competitivo, com mudanças cada vez mais rápidas e constantes no ambiente tanto local quanto global (ESTRADA; ALMEIDA, 2007).

Neste cenário, é possível identificar a adoção de novas práticas no que diz respeito à estrutura das organizações. No final do século passado, Huber e Glick (1995) já haviam chamado a atenção para algumas dessas práticas, como a composição de times, o achatamento da hierarquia, a busca por funcionários multifuncionais, o uso de tecnologias flexíveis e a adoção de homeoffice. Entretanto, é possível constatar que tais práticas continuam recebendo notoriedade tanto no ambiente empresarial, como é o caso dos estudos de Hamel (2011) e Jabbour e Santos (2013), quanto em organizações sem fins lucrativos, como demonstram as pesquisas de Flach (2011) e Barcellos e Dellagnelo (2013), por exemplo. Inclusive, Barreto et al. (2011) acentuam que, no que diz respeito às tendências na área de administração, o processo de trabalho flexível encontra-se entre os temas mais pesquisados nos últimos cinco anos.

Desse modo, parece não haver dúvidas sobre a utilização de práticas inovadoras nas organizações ao longo do tempo, principalmente quando comparadas ao padrão burocrático característico das organizações mecânicas (VOLBERDA, 1998; MINTZBERG, 2008). Estas novas ações impulsionaram novas estruturas organizacionais, como as configurações adhocrática (MINTZBERG, 2008) e de autogestão (HAMEL, 2011), por exemplo. Contudo, percebe-se que não há consenso sobre o tema, pois, enquanto alguns autores, como Clegg (1990) e Parker (1992), entendem tais práticas como a representação da desdiferenciação do modelo burocrático, autores como Tsoukas (1992) e Volberda (1998) afirmam que as novas práticas identificadas nas organizações atuais representam uma adaptação organizacional diante do ambiente externo, o que indica que o modelo weberiano estaria apenas sendo flexibilizado.

Diante das discussões identificadas na literatura, a presente pesquisa parte do princípio de que as novas práticas organizacionais estão relacionadas à compreensão estratégica das 
organizações; logo, visam à constante adaptação ao ambiente em que estão inseridas (SUAREZ; CUSUMANO; FINE, 1995; VOLBERDA, 1996). Assim, quanto mais dinâmico é o ambiente, mais orgânica deve ser a estrutura organizacional. A estrutura organizacional pode estar em um continuum entre mecânica e orgânica, que corresponde ao potencial de flexibilidade estrutural que a organização possui (Volberda, 1998; Mintzberg, 2008).

Ainda que em décadas passadas as estruturas organizacionais tradicionais tenham sido eficazes em ambientes relativamente estáveis, as alterações no grau de turbulência dos ambientes têm alterado de forma considerável os parâmetros de competição mercadológica, sobretudo em decorrência da evolução da tecnologia. Assim, ao invés de longos e estáveis períodos em que as organizações poderiam obter uma vantagem competitiva, a competição é cada vez mais caracterizada por vantagens de curtos períodos, pontuados por frequentes interrupções (VOLBERDA, 1998; SOARES; TEIXEIRA; PELISSARI, 2011).

Desse modo, é possível perceber que o futuro das estruturas organizacionais não está relacionado com as prescrições tradicionais do modelo burocrático, que buscam o controle de cima para baixo, o gerencialismo, o mecanicismo e o alto grau de hierarquia. A flexibilidade está, progressivamente, tornando-se a marca de excelência organizacional, até mesmo porque a gestão flexível estimula a criatividade, a inovação e a velocidade em um ambiente em que é preciso manter a coordenação, o foco e o controle (VOLBERDA, 1998; HAMEL 2011).

A importância do potencial de flexibilidade ocorre em virtude da necessidade das constantes mudanças que impactam os processos estratégicos das organizações. Nesse sentido, Verdú-Jover, Lloréns-Montes e García-Morales (2004) concebem que a flexibilidade influencia mais o desempenho das organizações prestadoras de serviços do que o das indústrias de manufatura. Assim, as empresas de serviços, como é o caso da Cooperativa de Trabalho Médico, objeto de estudo da presente pesquisa, devem ter a capacidade de mudar quando as práticas no ambiente externo se alteram.

Na realidade da Cooperativa, é possível constatar diversos fatores que exigem esta capacidade, tais como: o mercado de saúde suplementar é regulamentado pela Agência Nacional de Saúde Suplementar (ANS), que constantemente estabelece novas leis e normativas; o modelo de gestão é cooperativista, o que por si só aumenta a complexidade interna da organização; a competitividade aumenta em decorrência da estruturação de novos concorrentes; e existem outras exigências comerciais, econômicas e políticas que permeiam qualquer segmento de mercado. Diante do exposto, esta pesquisa visa analisar o potencial de flexibilidade estrutural de uma Cooperativa de Trabalho Médico sob a ótica da coalizão dominante.

\section{REFERENCIAL TEÓRICO}

\subsection{COOPERATIVISMO}

Entende-se por cooperativa a junção independente de pessoas que se unem voluntariamente para satisfazer interesses comuns de natureza econômica, social e cultural, por meio de uma empresa de propriedade coletiva e gerida democraticamente (BENATO, 2004). Para Benato (2004), as organizações cooperativas são negócios sem o objetivo final de lucro, administradas democraticamente pelos sócios. Trata-se de um empreendimento entre indivíduos do mesmo ramo de atuação ou com os mesmos interesses, que se unem para aperfeiçoar suas condições socioeconômicas e culturais e oferecer à sociedade seus serviços. 
O modelo das empresas cooperativistas está intimamente ligado ao desenvolvimento e à integração social. Alves (2003) afirma que a cooperação, quando organizada segundo estatutos previamente estabelecidos, origina determinados grupos sociais. Turra, Santos e Colturato (2002) corroboram este conceito quando afirmam que o cooperativismo consiste em uma forma de organização social que se mobiliza e se consolida em torno das cooperativas, tendo como finalidade principal a difusão dos ideais nos quais estão embasadas.

Uma vez motivadas pelos objetivos sociais do trabalho, as práticas cooperativistas orientam-se pelos seguintes princípios: adesão livre e voluntária; controle democrático pelos sócios; participação econômica dos sócios; autonomia e independência; educação, treinamento e informação; cooperação entre cooperativas; e preocupação com a comunidade (BENATO, 2004). Os princípios básicos do cooperativismo, de acordo com a Organização das Cooperativas Brasileiras (OCB) (2013), são: adesão voluntária e livre, gestão democrática, participação econômica dos membros, autonomia e independência, educação, formação e informação, intercooperação e interesse pela comunidade.

Logo, o conceito de cooperativas pode ser entendido como organizações que não buscam o lucro e são administradas democraticamente pelos próprios sócios, sendo empreendimentos entre pessoas do mesmo ramo de atuação e com os mesmos interesses. Essas pessoas se unem através da ajuda mútua com a finalidade de conquistar melhores condições socioeconômicas e culturais, proporcionando à sociedade suas competências na forma de trabalho, bens ou serviços (RICCIARDI; LEMOS, 2000). Neste mesmo sentido, Alves (2003) define cooperativas médicas como organizações caracterizadas pela economia de ajuda mútua, em que os objetivos econômicos e sociais são comuns a todos. Irion (1994) salienta que os aspectos legais e doutrinários das cooperativas médicas diferem dos de outras empresas por não possuírem o lucro como a razão de sua existência.

É importante mencionar que a Cooperativa em análise neste estudo de caso possui algumas peculiaridades, sobretudo no que diz respeito à relação entre as atividades médicas e as atividades administrativas, ou seja, entre as atividades-fim e as atividades-meio do processo produtivo. As atividades médicas dos cooperados envolvem consideráveis ações do corpo administrativo em termos de apoio e gestão de negócio, principalmente porque os cooperados são, concomitantemente, proprietários e prestadores de serviço. Assim, embora seja uma Cooperativa de Trabalho Médico, existe um número significativo de funcionários organizados burocraticamente e que prestam serviços de apoio à atividade-fim da Singular.

Embora o lucro não faça parte da natureza da organização em estudo, é possível identificar um paradoxo nos atores deste tipo associativo, uma vez que a organização é, ao mesmo tempo, social e econômica. Gonçalves (2003) relata que é social porque é formada por pessoas que participam da sociedade e é econômica uma vez que busca resultados financeiros, apesar de ser considerada uma cooperativa.

Nesse sentido, torna-se relevante abordar alguns pontos, como a essência cooperativista, o crescimento quantitativo e empresarial e a substituição dos valores do cooperativismo pela eficiência econômico-administrativa. Estes fatores decorrem da necessidade de responder de modo eficaz ao desafio da competitividade, sobretudo após a entrada das grandes empresas multinacionais no mercado interno (GONÇALVES, 2003).

Portanto, percebe-se que as organizações caracterizadas pelo cooperativismo possuem individualidades, principalmente no que diz respeito à estrutura organizacional. Desse modo, é importante que tais características sejam compreendidas, principalmente quando o objetivo é analisar o potencial de flexibilidade estrutural. 


\subsection{FLEXIBILIDADE ORGANIZACIONAL}

Antes de abordar os estudos acerca da estrutura, vale destacar o entendimento e a importância da flexibilidade organizacional na amplitude do seu conceito. Na concepção de Guimarães e Silva (2000), o conceito de flexibilidade é um termo que se encontra associado à ideia de inovação, de mudança e de capacidade de adaptação, de forma que a organização possa responder de modo eficiente às demandas sociais de seus clientes e dos demais agentes que compõem o seu ambiente externo.

Na concepção de Legge (1995), a flexibilidade organizacional é a reestruturação do processo e do mercado de trabalho para aumentar a versatilidade do modelo e estender a adaptabilidade a novas tecnologias de produção. Pode-se afirmar que os importantes avanços tecnológicos foram um dos fatores determinantes para o surgimento de novas organizações do trabalho, possibilitando o advento da flexibilidade organizacional.

Nesse sentido, um ambiente competitivo pode influenciar as organizações a movimentarem-se mais rapidamente, já que as organizações que apresentam estruturas mais flexíveis tendem a ter maior capacidade de se adequar ao ambiente externo. A partir disso, presume-se que, diante de um ambiente em significativa mutação, é arriscado que as organizações insistam no funcionamento regular dos seus processos, pois sem flexibilidade podem ter a sua sobrevivência ameaçada (VOLBERDA, 1996; 1998).

Verdú-Jover, Lloréns-Montes e García-Morales (2004) também destacam a importância da flexibilidade em relação à adaptação estratégica. Estes pesquisadores examinaram as diferenças existentes em relação ao desempenho nos níveis de ajuste entre a flexibilidade real e a flexibilidade exigida pelo ambiente em um nível estratégico, estrutural e operacional em 417 empresas localizadas na Europa. A pesquisa de Verdú-Jover, Lloréns-Montes e García-Morales (2004) indica que a flexibilidade influencia mais o desempenho das empresas de serviços do que das indústrias de manufatura. Desse modo, as organizações prestadoras de serviços devem ter a capacidade de se adaptar estrategicamente às exigências impostas pelo ambiente.

Vale destacar que a Cooperativa de Trabalho Médico passa, nos últimos anos, por frequentes mudanças, o que torna os princípios do potencial de flexibilidade ainda mais importantes. Volberda (1998) profere que esse potencial está relacionado a três dimensões: estrutura, tecnologia e cultura. Assim, levando em consideração os objetivos da presente pesquisa, tornase oportuno aprofundar a discussão sobre estrutura organizacional.

\subsubsection{Estrutura organizacional}

Inicialmente, torna-se essencial apresentar algumas definições do que vem a ser a estrutura disposta nas organizações, pois, de acordo com Drucker (1977, p. 555),

a melhor das estruturas não será capaz de assegurar qualquer resultado ou desempenho, mas a estrutura errada garante o mau desempenho. Tudo que ela gera são atritos e frustrações. A estrutura errada realça os pontos que não devem ser realçados, aprofunda as disputas desimportantes e levanta tempestades sobre questões triviais. Ela salienta as deficiências, em vez de virtudes.

Apesar de não garantir o desempenho, a estrutura é fundamental para o correto funcionamento da organização, uma vez que uma estrutura inadequada pode ter como decorrência o fracasso organizacional (Blenko; Mankins; Rogers, 2010).

A estrutura organizacional é definida de diversas formas na literatura (VOLBERDA, 1998). 
Para Mintzberg (2008, p. 12), "a estrutura de uma organização pode ser simplesmente definida como a soma total das maneiras pelas quais o trabalho é dividido em tarefas distintas e como é feita a coordenação entre as tarefas". Por outro lado, após afirmar que a estrutura organizacional pode ser entendida como a combinação das partes organizacionais, Hall (2004) apresenta a sua concepção de estrutura organizacional a partir de uma analogia com a estrutura de edifícios.

Segundo Hall (2004), os edifícios possuem portas pelas quais as pessoas entram e saem, assim como as organizações têm portões de entrada, como o setor onde são realizadas as matrículas de uma universidade, por exemplo. Além disso, elas possuem regras e procedimentos que orientam as ações diárias dos funcionários, e os edifícios possuem passagens e corredores que atendem à finalidade dos indivíduos que ali transitam. Ainda, do mesmo modo que se configuram as organizações, alguns edifícios são pequenos e simples, enquanto outros são complexos e com diversos níveis. Contudo, o autor ressalta que esta analogia não é perfeita devido ao caráter emergente que a estrutura organizacional possui, diferentemente da estrutura de um edifício. Isto é, a estrutura de uma construção pode não ser alterada por décadas, ao contrário das estruturas organizacionais que se alteram "continuamente, à medida que são influenciadas por grupos sucessivos de membros, pela interação entre eles e pelas mudanças ambientais contínuas" (HALL, 2004, p. 45).

Kast e Rosenzweig (1987) consideram que a estrutura organizacional é um padrão estabelecido para as relações entre os membros ou as partes da organização. Vasconcellos e Hemsley (1997) complementam que a estrutura organizacional seria o resultado do modo como: a autoridade é distribuída, as atividades desde os níveis mais baixos até a alta administração são definidas e um sistema de comunicação é delineado, permitindo que os indivíduos consigam realizar suas atividades e exerçam a autoridade que lhes compete para o alcance dos objetivos organizacionais.

Para Bate, Khan e Pie (2000), a estrutura de uma organização descreve não apenas as prescrições formais do desenho organizacional, mas também as configurações de interações que ocorrem dentro de uma empresa. Essa estrutura também facilita o alcance de objetivos por meio do estabelecimento de certos tipos de conduta, que fornecem suporte para formas de comprometimento e limitam aqueles que rejeitam os fundamentos estabelecidos.

A estrutura não pode ser pensada, no entanto, sem que algumas questões sejam analisadas. Hall (2004) argumenta que as questões centrais da estrutura de uma organização formamse a partir da complexidade, da formalização e da centralização. A complexidade assume diversas formas, incluindo a diferenciação horizontal, a diferenciação vertical e a dispersão espacial. A formalização, por sua vez, envolve o grau de pré-programação do comportamento individual na organização, ou seja, o controle sobre o indivíduo, e está relacionada à opinião dos responsáveis pelo processo decisório acerca da capacidade de julgamento e autocontrole dos membros organizacionais. Já a centralização se refere à distribuição de poder antecipadamente definida na organização (HALL, 2004).

Sob outra perspectiva, abordando principalmente o nível do potencial de flexibilidade de determinada estrutura organizacional, Volberda (1996) afirma que a estrutura não é apenas a distribuição de autoridade e responsabilidade entre os membros da organização - ou seja, a forma básica -, pois ela corresponde também ao planejamento, aos sistemas de controle, à coordenação dos processos de trabalho e à execução destas atividades. Assim como Volberda (1996; 1998), Hall (2004) e Mintzberg (2008) proferem que o desenho estrutural de uma organização pode variar de mecanicista a organicista; no entanto, Volberda (1998) vai além quando propõe um referencial metodológico para analisar em que ponto específico a organização está situada neste continuum. 
Se as estruturas consideradas mecânicas são aquelas pautadas no modelo weberiano, as novas práticas de gestão abrem caminho para estudos sobre as possíveis novas estruturas organizacionais, que correspondem ao que Volberda (1998) denomina de estruturas orgânicas. Um exemplo disso é a concepção de autogestão. Para Hamel (2011), a autogestão concebe uma forma de trabalhar em que ninguém tem chefe, os funcionários negociam suas responsabilidades com os próprios pares, todos podem desembolsar dinheiro da empresa e todos são responsáveis por obter as ferramentas e a matéria-prima necessária para desempenhar suas funções. Hamel (2011) identificou que é possível se estruturar a partir destas características, uma vez que a Morning Star Company, por exemplo, maior processadora de tomates do mundo, configura-se desta forma há mais de 20 anos.

Percebem-se algumas questões convergentes entre as concepções de Volberda (1998), Mintzberg (2008) e Hamel (2011), principalmente no que diz respeito às vantagens e desvantagens de modelos flexíveis. As principais vantagens estão relacionadas à redução de custos, à maior iniciativa por parte dos funcionários, ao conhecimento mais profundo, ao maior índice de decisões assertivas e à maior flexibilidade. Já as principais desvantagens referem-se à difícil e lenta adaptação, aos desafios de desempenho e aos possíveis problemas de promoção (VOLBERDA, 1998; MINTZBERG, 2008; HAMEL, 2011).

Diante do exposto, considerando as características que a organização apresenta, é possível analisar o seu potencial de flexibilidade estrutural. Nesse sentido, Volberda (1998) concebe que este potencial se refere à maior ou menor flexibilidade organizacional em decorrência de uma estrutura orgânica ou mecânica.

\subsubsection{Potencial de flexibilidade estrutural}

Aborda-se nesta seção o referencial metodológico de Volberda (1998), em que a presente pesquisa se embasa para realizar este estudo de caso. Segundo o autor, utilizando a análise da forma organizacional básica, do sistema de planejamento e controle e dos processos de regulação, é possível identificar o potencial de flexibilidade estrutural. O Quadro 1, exposto a seguir, ilustra o conteúdo apresentado nesta seção.

Quadro 1: Potencial de flexibilidade estrutural

\begin{tabular}{|c|c|c|c|c|}
\hline SUBDIMENSÃO & INDICADORES & $\begin{array}{c}\text { MECÂNICA } \\
\text { (baixo potencial de } \\
\text { flexibilidade) }\end{array}$ & & $\begin{array}{c}\text { ORGÂNICA } \\
\text { (alto potencial } \\
\text { de flexibilidade) }\end{array}$ \\
\hline \multirow{3}{*}{$\begin{array}{l}\text { Forma organi- } \\
\text { zacional básica }\end{array}$} & Agrupamento & Funcional & $\begin{array}{l}\text { Bens/ser- } \\
\text { viço }\end{array}$ & Mercado-alvo \\
\hline & Níveis hierárquicos & Muitos/alta & & Poucos/achatada \\
\hline & Funcionalizacão & Alta & & Baixa \\
\hline \multirow{3}{*}{$\begin{array}{l}\text { Sistema de pla- } \\
\text { nejamento e } \\
\text { controle }\end{array}$} & $\begin{array}{l}\text { Regulação de objetivos e defini- } \\
\text { ção de prioridades }\end{array}$ & Elaborado & & Rudimentar \\
\hline & $\begin{array}{l}\text { Programação interna de plane- } \\
\text { jamento }\end{array}$ & Elaborado & & Rudimentar \\
\hline & $\begin{array}{l}\text { Controle de progresso e ava- } \\
\text { liação }\end{array}$ & Elaborado & & Rudimentar \\
\hline
\end{tabular}




\begin{tabular}{|c|c|c|c|c|}
\hline SUBDIMENSÃO & INDICADORES & $\begin{array}{c}\text { MECÂNICA } \\
\text { (baixo potencial de } \\
\text { flexibilidade) }\end{array}$ & & $\begin{array}{c}\text { ORGÂNICA } \\
\text { (alto potencial } \\
\text { de flexibilidade) }\end{array}$ \\
\hline \multirow{14}{*}{$\begin{array}{l}\text { Processos de } \\
\text { regulação }\end{array}$} & \multicolumn{4}{|c|}{ Regulação de tarefas } \\
\hline & 1. Amplitude da tarefa & Estreita & & Ampla \\
\hline & 2. Profundidade da tarefa & Simples & & Complexa \\
\hline & 3. Intercambialidade & Baixa & & Alta \\
\hline & \multicolumn{4}{|c|}{ Regulação do comportamento } \\
\hline & 1. Padronização & Alta & & Baixa \\
\hline & 2. Formalização & Alta & & Baixa \\
\hline & 3. Treinamento e educação & Baixo/rotineiro & $\begin{array}{c}\text { Alto/profis- } \\
\text { sional }\end{array}$ & Artífice \\
\hline & \multicolumn{4}{|c|}{ Regulação de ajustes mútuos } \\
\hline & 1. Dispositivos de contatos & Forma de influência & Grupo & Forma natural \\
\hline & 2. Descentralização horizontal & Muito unidos & & Pouco unidos \\
\hline & \multicolumn{4}{|c|}{ Regulação da tomada de decisão } \\
\hline & 1. Delegação & Baixa & & Alta \\
\hline & 2. Participação & Baixa/exclusiva & & Alta/participativa \\
\hline
\end{tabular}

Fonte: adaptado de Volberda (1998)

Vale ressaltar que, assim como o quadro supracitado, as definições que seguem estão embasadas nas concepções de Volberda (1998). A primeira subdimensão refere-se à forma organizacional básica, que se divide em modo de agrupamento, níveis hierárquicos e grau de funcionalização administrativa.

Entende-se por agrupamento a maneira pela qual a organização envolve os indivíduos, as atividades, as unidades, os núcleos e assim por diante, até que se tenha um grupo unido em um mesmo contexto. É possível identificar três formas básicas de agrupamento: funcional - baseada no conhecimento e nas habilidades, no processo de trabalho e na função; bens/serviço - a divisão é realizada com base nos bens ou serviços ofertados; mercado-alvo - dividido por localidades, base de clientes, dentre outros. Quanto maior a utilização da divisão funcional, menor o potencial de flexibilidade da organização. Por outro lado, se a opção é a utilização de mercado-alvo, a organização passa a ter mais aproximação com o organicismo.

Quanto à análise do nível hierárquico, é possível identificá-lo como a forma pela qual o poder está subdividido na organização. Uma organização com poucos níveis hierárquicos é considerada orgânica, ao passo que organizações com diversos níveis hierárquicos podem ser consideradas mecânicas ou com menor potencial de flexibilidade.

Já a funcionalização se refere ao entendimento de como as áreas funcionais da organização estão alocadas. Em determinada organização com alta funcionalização, a divisão das responsabilidades é clara entre os indivíduos que gerenciam ou planejam e os indivíduos que apenas executam as tarefas operacionais. É possível definir que, em uma organização com alta funcionalização, cada cargo ou núcleo é especializado e responsável por uma função específica.

O sistema de planejamento e controle, segunda subdimensão de acordo com o referencial metodológico de Volberda (1998), consiste no modo como ocorre a regulação de objetivos e definição de prioridades, a programação interna de planejamento e o controle de progresso e sua avaliação. Sua análise pode resultar em dois extremos: elaborado e rudimentar. 
A análise destes fatores é realizada a partir da forma como a organização utiliza seus sistemas internos. Assim, quanto mais meticulosas e detalhadas forem estas ações, menor será sua capacidade de flexibilidade estrutural. Isso ocorre porque os sistemas rudimentares são considerados mais abertos e adaptativos, uma vez que, ao invés de objetivar o determinismo e o controle específicos de ações, abrem espaços para experimentos e ações intuitivas, promovendo soluções relativamente originais para novos problemas e tomadas de decisões urgentes. Os sistemas rudimentares caracterizam-se pela maior abertura à participação dos funcionários no processo de planejamento, por metas qualitativas de longo prazo que deixam margem para avaliações subjetivas e por poucos sistemas internos de avaliação e controle. Portanto, trata-se de um dos principais pontos de discussão no que diz respeito ao desafio de manter a coordenação, o foco e principalmente o controle em organizações orgânicas.

A terceira subdimensão apresentada por Volberda (1998) refere-se aos processos de regulação, podendo ser dividida em regulação de tarefas, regulação do comportamento, regulação de ajustes mútuos e regulação da tomada de decisão. No que diz respeito à regulação das tarefas, destacam-se os seguintes indicadores: amplitude da tarefa - variabilidade das tarefas executadas pelos indivíduos; profundidade da tarefa - grau de controle sobre as suas próprias atividades; e intercambialidade - possível troca de papéis/funções com os demais indivíduos da organização. A partir da análise destes indicadores, é possível identificar se a regulação das tarefas possui características de baixo ou alto potencial de flexibilidade.

Por regulação do comportamento, entende-se o nível no qual os comportamentos dos indivíduos são programados com antecedência. A identificação deste fator ocorre por intermédio do resultado da análise dos seguintes indicadores: padronização - modo como as atividades dos funcionários são especificadas e programadas; formalização - forma pela qual o comportamento é definido com base em descrições e prescrições, resultando no nível em que as regras, os procedimentos e as comunicações são formalizados por meio de documentos; e treinamento e educação - capacitação dos indivíduos para a execução das suas atividades cotidianas.

A regulação de ajustes mútuos diz respeito à identificação dos meios de comunicação e processos de tomada de decisão em conjunto com vários indivíduos independente do seu núcleo ou departamento e cargo - ou seja, cruzam as linhas dos níveis hierárquicos e da funcionalização de uma organização. Logo, quanto mais natural for o contato entre os indivíduos de diferentes áreas e menor for a dependência de uma unidade em relação às demais, maior será o seu potencial de flexibilidade no que refere aos ajustes mútuos de uma organização.

É possível compreender a regulação da tomada de decisão como a participação de diferentes níveis hierárquicos na efetiva tomada de decisão por meio do compartilhamento de informações, a abertura para opiniões ou a distribuição do poder de decisão nas camadas hierárquicas inferiores. Desse modo, conclui-se que a análise do potencial de flexibilidade é realizada por intermédio da delegação e participação na tomada de decisão.

De acordo com Volberda (1998), utilizando as subdimensões e os indicadores supracitados, é possível identificar o predomínio de aspectos mecanicistas ou organicistas em determinada estrutura organizacional. Por estruturas mecânicas, entendem-se as organizações com: alto nível hierárquico, divisão funcional, processos altamente regulados por sistemas de planejamento e controle e alto processo de regulação de tarefas, de comportamento, de ajustes mútuos e de tomada de decisão. Já em estruturas consideradas orgânicas, o potencial de flexibilidade é alto devido à adoção de divisão matricial, com hierarquias enxutas, sistema de planejamento e controle focado no resultado, dentre outras características. 


\section{PROCEDIMENTOS METODOLÓGICOS}

Este artigo é resultado de uma pesquisa qualitativa, com objetivo de caráter descritivo, delineada pela estratégia de pesquisa de estudo de caso. 0 processo de pesquisa seguiu o referencial metodológico de Yin (2009), o qual afirma que, para desenvolver um estudo de caso consistente, é necessário seguir cinco etapas: delineamento da pesquisa; desenho da pesquisa; preparação e coleta dos dados; análise dos casos; e elaboração dos relatórios. Ainda que não sejam apresentadas por tópicos, as principais atividades desenvolvidas em cada etapa estão detalhadas no decorrer deste capítulo.

O primeiro passo foi desenvolver o protocolo de pesquisa. Além das categorias de análise e dos instrumentos de coleta de dados, este protocolo determinou as regras e os procedimentos que deveriam ser seguidos antes, durante e depois da coleta (YIN, 2009). As categorias de análise fundamentam-se no referencial metodológico de Volberda (1998) e referem-se aos seguintes indicadores: agrupamento, níveis hierárquicos, funcionalização, regulação de objetivos e definição de prioridades, programação interna de planejamento, controle de progresso e avaliação, amplitude da tarefa, profundidade da tarefa, intercambialidade das tarefas, padronização do comportamento, formalização do comportamento, treinamento e educação, dispositivos de contatos, descentralização horizontal, delegação e participação.

Contudo, é importante esclarecer que estes indicadores, que juntos constituem a subdimensão forma organizacional básica, a subdimensão sistema de planejamento e controle e a subdimensão processos de regulação do referencial metodológico de Volberda (1998), abrangem elementos abordados tanto em pesquisas clássicas, como nas obras de Hall (2004) e de Mintzberg (2008) quanto em pesquisas mais recentes, como é o caso de Blenko, Mankins e Rogers (2010) e Hamel (2011), por exemplo. Destarte, a justificativa por seguir este referencial metodológico consiste na sua consistência, na sua abrangência e na compatibilidade com o objetivo desta pesquisa.

Esta pesquisa teve como principal fonte a entrevista semiestruturada, além da utilização da pesquisa bibliográfica, da pesquisa documental e da observação direta sistemática. Inicialmente, empregou-se a pesquisa documental, que permitiu analisar os dados publicados em documentos e canais oficiais da Cooperativa, tais como estatutos, intranet, internet, atas de reuniões, manuais internos, materiais de campanhas publicitárias, leis e normativas da ANS. O conteúdo relacionado com as categorias de análise da pesquisa foi incluído na base de dados do estudo de caso e armazenado no Atlas.ti.

Posteriormente, coletaram-se os dados primários, principalmente por meio da entrevista em profundidade, com a utilização de roteiro semiestruturado. Entende-se que este método foi o mais adequado para a coleta de dados desta pesquisa, pois, além de possibilitar a identificação da percepção da coalizão dominante, permitiu complementar o roteiro de entrevista de acordo com o conteúdo das respostas e a disponibilidade de cada entrevistado (SILVERMAN, 2006). Como o objetivo consiste na análise do fenômeno sob a ótica da coalizão dominante, os entrevistados foram definidos de modo intencional, a saber: um Presidente, dois Diretores, um Assessor de Diretoria, dois Gerentes e dois Analistas. As entrevistas foram previamente agendadas e realizadas na estrutura física da Cooperativa, na maioria dos casos na sala de reuniões da Diretoria de Gestão. Após a realização de todas as entrevistas, que ocorreram entre dezembro de 2009 e fevereiro de 2010, o conteúdo foi transcrito e incluído na base de dados do estudo de caso.

Não obstante, a observação direta sistemática foi utilizada como fonte de validação dos dados coletados. Este processo foi desenvolvido entre maio de 2010 e março de 2011. O emprego deste método consistiu no acompanhamento frequente dos processos internos, na participa- 
ção como ouvinte em reuniões, na observação das atividades de auditoria do Sistema de Gestão da Qualidade e no recebimento das comunicações internas e externas, em que se destacam os comunicados relacionados às novas leis e normativas da ANS. Desse modo, a observação direta sistemática possibilitou examinar acontecimentos que colaboraram ou negaram determinados achados da pesquisa. Tais análises foram incluídas no Atlas.ti no decorrer do processo de coleta de dados, totalizando 42 Memos.

Assim, os dados primários e secundários constituíram a base de dados do estudo de caso, que, como recomenda Kelle (2004), foi armazenada no Atlas.ti. Posteriormente, identificaram-se nesta base de dados os trechos e as imagens que estivessem relacionadas com as categorias de análise da pesquisa (BARDIN, 1977). Portanto, iniciou-se o processo de análise de conteúdo utilizando como apoio o software de análise qualitativa de dados Atlas.ti (KELLE, 2004). Este processo possibilitou o desenvolvimento de 23 Codes e mais de 270 Quotes, que juntos auxiliaram os pesquisadores a compreender o potencial de flexibilidade estrutural da Cooperativa de Trabalho Médico.

A coleta de dados em diferentes fontes e com indivíduos de distintos níveis hierárquicos foi importante para o alcance dos critérios de validade do constructo (YIN, 2009; Gerring; McDermott, 2010), principalmente por intermédio da triangulação dos dados (Amis; Silk, 2008; YIN, 2009). Esta triangulação contou com a relação entre os dados formalizados nos documentos, relatados nas entrevistas e percebidos na observação direta sistemática, bem como na associação entre os dados informados por diferentes níveis hierárquicos, cargos e funções.

Este processo de pesquisa permitiu analisar o potencial de flexibilidade estrutural da Cooperativa em questão, conteúdo que é apresentado no capítulo seguinte.

\section{ANÁLISE DOS DADOS}

\subsection{CARACTERIZAÇÃO DO CASO}

A Cooperativa de Trabalho Médico analisada neste estudo de caso foi criada há mais de 40 anos por um grupo de 20 profissionais de medicina da região, como uma alternativa entre a medicina particular e previdenciária. Sobretudo pelo aumento da demanda, atualmente possui mais de 1.200 funcionários - que compõem seu corpo administrativo - e 1.600 médicos cooperados, cobrindo todas as especialidades médicas.

Os médicos cooperados prestam seus serviços por meio de estrutura própria e terceirizada. A estrutura própria é composta de três unidades de atendimento, que oferecem serviços de pronto-atendimento, laboratório médico, diagnóstico por imagem, aplicação de medicamentos, internação clínica e consultórios médicos eletivos. A estrutura de atendimento terceirizada, denominada rede prestadora, é constituída de 43 laboratórios, 39 hospitais e 250 clínicas.

Por se tratar de uma Cooperativa de Trabalho Médico, sua estrutura é formada por médicos cooperados e é dividida em Diretoria Executiva, Conselho Consultivo, Conselho de Administração e Conselho de Ética Cooperativista. A gestão é renovada a cada quatro anos por meio de assembleia geral, sendo eleita uma nova Diretoria Executiva que assume a representação dos cooperados no direcionamento das ações da Singular. A Diretoria Executiva tem como principal função a definição de rumos, tomada de decisões, formulação de estratégias e relação entre o mercado de planos de saúde e os interesses dos médicos cooperados. De acordo com as funções definidas no estatuto, cada diretor assume responsabilidades, áreas e departamentos específicos. 


\subsection{POTENCIAL DE FLEXIBILIDADE ESTRUTURAL DO CASO}

A primeira subdimensão analisada diz respeito à forma organizacional básica, que consiste em três indicadores: agrupamento, níveis hierárquicos e funcionalização. A organização é caracterizada pelo baixo potencial de flexibilidade no se refere à forma de agrupamento, já que utiliza o sistema de divisão de trabalho por funções. Ou seja, conforme indicam Volberda (1998) e Mintzberg (2008), os funcionários são agrupados de acordo com suas habilidades profissionais. Algumas áreas de relacionamentos - principalmente a área de relacionamento com o cooperado e relacionamento com importantes clientes pessoa jurídica - possuem divisões por segmentação em casos específicos, o que representa também um estilo de divisão por mercado. Porém, considerando o amplo contexto, isso não altera sua caracterização como forma tradicional de alocação da força de trabalho.

Mesmo em uma organização de grande porte, o nível hierárquico com seis camadas de poder pode ser considerado alto (VOLBERDA, 1998). No atual organograma da Cooperativa de Trabalho Médico, identificou-se a composição de diretores executivos, diretores de gestão, gerentes, supervisores, líderes e assessores, além de analistas e assistentes. Este fator se torna relevante na caracterização mecânica da organização, uma vez que a comunicação é realizada gradualmente por meio dos níveis hierárquicos, o que diminui a velocidade da comunicação.

$\mathrm{Na}$ análise da funcionalização, identificou-se que cada cargo é especializado em determinado ramo de atuação, como, por exemplo, marketing, vendas, financeiro, produção médico, dentre outros. Isso significa que cada assunto específico é coordenado somente pelo responsável de cada área e sua respectiva equipe, levando em consideração o nível hierárquico. Tal fato resulta em uma alta funcionalização de autoridade e, consequentemente, em formas organizacionais básicas fragmentadas. Este fato vem de encontro às características de estruturas adhocráticas concebidas por Mintzberg (2008) e de autogestão identificadas na pesquisa de Hamel (2011), por exemplo. Assim, a funcionalização da Cooperativa caracteriza-se pelo baixo potencial de flexibilidade.

A segunda subdimensão analisada refere-se ao sistema de planejamento e controle, que consiste em três indicadores: regulação de objetivos e definição de prioridades; programação interna de planejamento; e controle de progresso e sua avaliação (VOLBERDA, 1998). Na realidade da Cooperativa, a regulação de objetivos é geralmente realizada de forma top-down, de modo que os diretores executivos desenvolvem ações, que posteriormente são encaminhadas aos diretores de gestão e assim sucessivamente. Em determinados casos, a tomada de decisão é realizada por todos os médicos cooperados em assembleia geral; contudo, há casos em que os próprios gerentes ou supervisores elaboram metas e prioridades para suas equipes. Tratando o tema de forma ampla, a regulação dos objetivos e a definição de prioridades são realizadas de maneira elaborada, geralmente amparadas por projetos estratégicos de médio e longo prazo. Portanto, de acordo com o referencial metodológico de Volberda (1998), a regulação de objetivos da Cooperativa configura-se predominantemente como mecânica.

No que diz respeito à programação interna de planejamento e controle de progresso e avaliação, constatou-se a utilização de um escritório de projetos interno, que possui ferramentas de apoio para mensurar o resultado atingido. Este escritório é composto de um supervisor e uma série de analistas, que geralmente se relacionam com o líder do projeto, tanto estratégico quanto tático. Desse modo, o potencial de flexibilidade é baixo, pois, como concebe Volberda (1998), os projetos são basicamente de médio e longo prazo, não possuindo focos de sistema de planejamento rudimentar.

A terceira subdimensão analisada diz respeito aos processos de regulação, que consiste em quatro indicadores: regulação de tarefas, regulação do comportamento, regulação de ajustes 
mútuos e regulação da tomada de decisão. No que diz respeito à regulação das tarefas, é possível identificar ações características de estruturas tanto mecânicas quanto orgânicas. Em determinados aspectos, as tarefas possuem uma amplitude estreita, o que, consequentemente, resulta em baixa profundidade e intercambialidade; em contrapartida, em outros aspectos, esses fatores são proporcionalmente inversos (VOLBERDA, 1998). No que se refere à profundidade das tarefas, constatou-se focos de organicismo, pois os indivíduos coordenam suas próprias atividades (MINTZBERG, 2008; HAMEL, 2011), embora o controle possa ser realizado pelo gestor imediato por meio de indicadores ou reuniões periódicas. Por outro lado, sob a luz da amplitude das tarefas, identificou-se que cada núcleo realiza diversas atividades, o que favorece a troca de papéis entre os indivíduos e resulta em uma regulação mais ampla. Contudo, de modo geral, as tarefas possuem amplitude estreita, profundidade simples e intercambialidade baixa.

Não obstante, em relação à regulação das tarefas, torna-se importante mencionar as ações do departamento de sistema da qualidade, que é responsável pela elaboração e pelo acompanhamento de Procedimentos Sistêmicos (PS) e Procedimentos Operacionais (PO). As ações deste departamento tendem a promover o que Montana e Sarnov (1998) denominam de departamentalização, já que os indivíduos podem se empenhar mais no seu departamento do que no desempenho holístico da organização. Na maioria dos departamentos da Cooperativa, percebese que ocorrem trocas de papéis/tarefas constantes. Em contrapartida, as áreas são altamente especializadas somente nas suas tarefas específicas, o que gera desconhecimento das atividades e dos processos de outras áreas. 0 departamento de produção médica, por exemplo, processa todas as autorizações realizadas na rede prestadora, sendo estas informações a base para o departamento financeiro elaborar a fatura para o cliente. Porém, o departamento financeiro não conhece os processos do departamento de produção médica nem o departamento de produção médica tem conhecimento sobre os processos da rede prestadora e assim sucessivamente. Segundo Montana e Sarnov (1998), esta departamentalização tende a impactar negativamente o desempenho da organização. Assim, de acordo com o referencial metodológico de Volberda (1998), a regulação das tarefas caracteriza-se como predominantemente mecânica.

No que diz respeito à regulação do comportamento, constataram-se características de baixo potencial de flexibilidade (VOLBERDA, 1998). Principalmente nas áreas reconhecidas como front office, identificaram-se fortes indícios de previsibilidade no comportamento, tanto na abordagem ao cliente quanto na conclusão do atendimento. Nas demais áreas, é possível afirmar que a padronização está relacionada à forma de comunicação, que, na maioria das vezes, é realizada por meio de e-mails e reuniões. Considerando a forte departamentalização identificada na organização em estudo, é possível afirmar que cada área possui uma padronização específica de comportamento. A utilização de ponto eletrônico, de intranet e de portais de notícias internas e, principalmente, o uso de e-mail são aspectos que demonstram a alta formalização e padronização do comportamento. Não obstante, pode-se concluir que as ações de treinamento e educação são predominantemente do tipo artífice (VOLBERDA, 1998), considerando também as limitações de cada área de negócio. Ou seja, os treinamentos são realizados especificamente dentro de cada linha do processo produtivo, sendo oportuno ressaltar, neste caso, a utilização do "Projeto Mentor" em cada departamento ou divisão. Este projeto se embasa na seleção de um indivíduo responsável por ensinar os detalhes da área e da função para cada novo colaborador. Via de regra, o treinamento tende a ser realizado de maneira informal, no próprio ambiente de trabalho, de acordo com as necessidades de cada atividade/função.

Ao considerar as particularidades de cada área, é possível afirmar que o indicador de ajustes mútuos é mais um aspecto que pode restringir o potencial de flexibilidade estrutural 
(VOLBERDA, 1998). Na maioria dos casos, os dispositivos de contato são os e-mails e as ferramentas de projetos estratégicos e táticos, o que não impede, contudo, que tais contatos sejam realizados de forma natural, como por meio de uma conversa informal ou um telefonema. Nesse sentido, vale ressaltar a dependência entre as diversas áreas de negócios da Cooperativa, como, por exemplo, a relação entre autorização, produção médica, financeiro e contabilidade, fator que, como apontam Volberda (1998) e Hall (2004), tende a restringir a descentralização horizontal.

Por fim, constatou-se o predomínio de baixo potencial de flexibilidade no que diz respeito à regulação da tomada de decisão (VOLBERDA, 1998). A maioria das decisões da Cooperativa é tomada buscando a adaptação ao ambiente, ou seja, referem-se às ações para se adaptar às constantes normativas governamentais, exigências de mercado e solicitações de importantes clientes, o que corrobora as concepções de Suarez, Cusumano e Fine (1995). Essas decisões geralmente são tomadas pelos Diretores Executivos e pelos Diretores de Gestão. Em alguns casos, existe a participação de níveis hierárquicos inferiores; contudo, esta participação não pode ser considerada alta, sobretudo porque geralmente se restringe às atividades operacionais.

Outro ponto importante é o contexto político em que a Cooperativa está inserida, pois faz parte de um sistema nacional composto de centenas de Singulares e Federações Estaduais que abrange todo o país. Por se tratar de uma cooperativa de trabalho médico que se caracteriza como uma burocracia profissional (MINTZBERG, 2008), é possível concluir que os médicos cooperados possuem fortes influências, o que pode ser um aspecto limitador à participação dos funcionários no processo de tomada de decisão, principalmente porque interesses pessoais ou institucionais podem ser praticados em detrimento dos resultados técnicos. Vale ressaltar que não há restrição para sugestões dos funcionários, mas nem sempre suas opiniões são levadas em consideração.

\section{CONSIDERAÇÕES FINAIS}

Esta pesquisa visou avaliar o potencial de flexibilidade de uma Cooperativa de Trabalho Médico. Assim, mesmo considerando as constantes mudanças que impactam a gestão estratégica da Cooperativa analisada, percebeu-se que a estrutura organizacional possui baixo potencial de flexibilidade. Dentre as principais mudanças que impactam a organização, destacam-se as exigências regulamentais da ANS, o modelo cooperativista que a cada quatro anos altera a composição do nível estratégico da organização, o aumento da competitividade em decorrência do surgimento de novos competidores e os aspectos que permeiam qualquer segmento de mercado.

O resultado da análise do potencial de flexibilidade estrutural, de acordo com o quadro de análise de Volberda (1998), demonstrou que diversos indicadores são altamente mecânicos. Não obstante, constatou-se que algumas ações internas tendem a restringir o potencial de flexibilidade da organização e incentivar ainda mais a departamentalização, como as atividades do escritório de projetos e a certificação do sistema de qualidade ISO 9001:2008. Ou seja, o fato de determinado núcleo estar mais preocupado com o seu departamento do que com as diretrizes organizacionais pode se tornar um empecilho para a eficácia da organização (MONTANA; SARNOV, 1998).

Além das exigências mercadológicas e das ações internas, é possível afirmar que dois fatores podem contribuir para o baixo potencial de flexibilidade da Cooperativa de Trabalho Médico. O primeiro está relacionado com o tamanho, uma vez que a literatura aponta que, quanto maior a organização, maior a centralização (MINTZBERG; QUINN, 2001; HALL, 2004; HREBINIAK, 2006). Nesse sentido, quanto maior for o tamanho da organização, maior será a tendência de a estrutura ser mais elaborada e, consequentemente, de as atividades serem mais especializadas 
(MINTZBERG, 2008). Desse modo, considerando a expressiva quantidade de funcionários e o alto faturamento - cerca de 600 milhões por ano -, percebe-se que o tamanho é um dos principais elementos que influenciam o baixo potencial de flexibilidade estrutural.

O segundo aspecto é o modelo de gestão cooperativista, que resulta no fato de diversos processos serem acompanhados e influenciados por mais de 1.600 médicos cooperados, exigindo, assim, um alto nível de controle, tanto dos processos quanto dos recursos. Hall (2004) explicita que este fato também pode estar relacionado ao porte da organização, indicando uma relação proporcional entre o tamanho e a necessidade de supervisão e formalização do comportamento.

Dessa forma, apesar de algumas particularidades, constatou-se que a Cooperativa de Trabalho Médico possui um baixo potencial de flexibilidade estrutural, o que pode ser um aspecto limitador às constantes adaptações e mudanças estratégicas (SVEIBY, 1992; HALL, 2004; HREBINIAK, 2006; MINTZBERG, 2008), principalmente considerando as exigências legais, uma vez que o negócio da organização é regulamentado por um órgão federal.

Vale destacar que a presente pesquisa buscou analisar uma das dimensões do referencial metodológico de Volberda (1998). Assim sendo, recomenda-se que sejam realizados outros estudos abordando o potencial de flexibilidade cultural e tecnológico, bem como as demais dimensões do quadro de análise desse autor, principalmente em organizações cooperativistas, uma vez que elas possuem características peculiares e complexas. Esta recomendação está pautada, além da realização do teste empírico de uma teoria, na evolução prática do entendimento do potencial de flexibilidade organizacional, já que a teoria demonstra que a flexibilidade estará cada vez mais presente no contexto estratégico das organizações.

\section{REFERENCIAS}

ALVES, M. A. P. Cooperativismo: arte \& ciência. Doutrina, prática e legislação. São Paulo: Livraria e Editora Universitária de Direito Ltda., 2003.

AMIS, J. M.; SILK, M. L. The philosophy and politics of quality in qualitative organizational research. Organizational Research Methods, v.11, n.3, p.456-480, 2008.

BARCELLOS, R. R.; DELLAGNelO, E. H.L. Reposicionando nossas concepções sobre práticas organizacionais: o Circuito Fora do Eixo e práticas organizacionais contra hegemônicas. In: EnAnpad, Rio de Janeiro. Anais do XXXVII EnAnpad. Rio de Janeiro: Anpad, 2013.

BARDIN, L. Análise de conteúdo. Lisboa: Edições 70, 1977.

BARRETO, L. M. T. S.; SILVA, M. P.; FISCHER, A. L.; ALBUQUERQUE, L. G.; AMORIM, W. A. C. Temas emergentes em gestão de pessoas: uma análise da produção acadêmica. Revista de Administração da UFSM, v. 4, n.1, p. 215-232, 2011.
BATE, P.; KHAN, R.; PIE, A. Towards a culturally sensitive approach to organization structuring: where organization design meets organization development. Organization Science, v.11, n.2, p.197-211, mar./apr. 2000.

BENATO, J. V. $\mathbf{O}$ abc do cooperativismo. 7. ed. São Paulo: CESP/SESCOOP -SP, 2004..

BLENKO, M. W.; MANKINS, M. C.; ROGERS, P. The decision-driven organization. Harvard Business Review, v. 88, issue 6, p. 54-62, 2010. Disponível em: <http://web.ebscohost.com/ ehost/pdfviewer/pdfviewer?sid=eb64b5831388-4b33-ac3a-4df59187a8b3\%40sessionmg r12\&vid=12\&hid=1>. Acesso em 17 jul. 2013.

CLEGG, S. Modern organizations: organization studies in the postmodern world. London: Sage Publications, 1990.

DRUCKER, P. F. Introdução à administração. São Paulo: Pioneira, 1977.

ESTRADA, R. J. S.; ALMEIDA, M. I. R. A eficiência e a eficácia da gestão estratégica: do planejamento estratégico à mudança 
organizacional. Revista de Ciências da Administração, v. 9, n. 19 , p. 147-178, set./ dez, 2007.

FLACH, L. A autogestão ensinando e encenando: um estudo etnográfico em uma organização cultural de PortoAlegre. Revista de Administração da UFSM, v. 4, n. 3, p. 378-389, 2011.

GIL, A. C. Como elaborar projetos de pesquisa. São Paulo: Atlas, 1991.

GONÇALVES, C. S. Uma contribuição à estruturação dos procedimentos e demonstrações contábeis das Cooperativas de Trabalho - Aplicação em uma Cooperativa de Trabalho. 2003. 180f. Dissertação (Mestrado em Ciências Contábeis) -Departamento de Contabilidade e Atuária, Faculdade de Economia, Administração e Contabilidade, Universidade de São Paulo, 2003.

GUIMARÃES, T. A.; SILVA, E. R. F. Autonomia e flexibilidade na gestão da regulação dos setores de energia elétrica e de telecomunicações no Brasil. In: ENCONTRO ANUAL DO CLAD, Cidade do México. Anais... Cidade do México: CLAD, 2000.

HALL, R. H. Organizações: estrutura, processos e resultados. 8. ed. São Paulo: Pearson Prentice Hall, 2004.

HAMEL, G. First, let's fire all the managers. Harvard Business Review, v. 89, issue 12, p. 48-60, 2011. Disponível em: <http:// web.ebscohost.com/ehost/pdfviewer/ pdfviewer?sid=eb64b583-1388-4b33-ac3a-4df 59187a8b3\%40sessionmgr12\&vid=8\&hid=1>. Acesso em 17 jul. 2013.

HUBER, G. P.; GLICK, W. H. Organizational change and redesign: ideas and insights for improving performance. New York: Oxford University Press, 1995.

IRION. J. E. Cooperativismo médico. Fale como dono. 2. ed. São Paulo: Cartaz, 1994.

JABBOUR, C. J. C.; SANTOS, F. C. A. Empowerment dos funcionários e níveis de maturidade da gestão ambiental nas empresas: um modelo conceitual. Revista de Administração da UFSM, v.6, n.3, p. 497-510, 2013.

KAST, F. E.; ROSENZWEIG, J. A. Organização e administração: um enfoque sistêmico. 3. ed. São Paulo: Pioneira, v.1, 1987.

KELLE, U. Análise com auxílio de computador: codificação e indexação. In: BAUER, M. W.; GASKELL, G. (Eds.). Pesquisa qualitativa com texto, imagem e som: um manual prático. Petrópolis: Vozes, p. 393-415, 2004.

LEGGE, K. Human resource management: Rhetorics and realities. London. Macmillan Business, 1995.

LINCOLN, Y. S.; GUBA, E. G. Naturalistic inquiry. Beverly Hills: Sage, 1985.

MONTANA, P. J.; SARNOV, B. H. Administração. São Paulo: Saraiva, 1998.

ORGANIZAÇÃO DAS COOPERATIVAS BRASILEIRAS (OCB). Cooperativismo: princípios. Disponível em: <http://www.ocb. org.br/site/cooperativismo/principios.asp>. Acesso em 12 de julho de 2013.

PARKER, M. Post-moderm organizations or postmodern organization theory? Organization Studies, v.13, n.1, p.35-54, 1992.

RANSON, S.; HININGS, B.; GREENWOOD, R. The structuring of organizational structures. Administrative Science Quarterly, v.25, n.1, p.1-17, 1980.

RICCIARDI, L.; LEMOS, R. J. Cooperativa, a empresa do século XXI : como os países em desenvolvimento podem chegar a desenvolvidos. São Paulo: LTR, 2000.

SILVERMAN, D. Interpreting qualitative data. London: Sage, 2006.

SUAREZ, F. F.; CUSUMANO, M. A.; FINE, C. H. An empirical study of flexibility in manufacturing. Sloan Management Review, 1995. 
SOARES, M. L.; TEIXEIRA, O. R. P.; PELISSARI, A. S. Comportamento organizacional: uma aplicação da tipologia de Miles e Slow no setor hoteleiro de Florianópolis-SC. Revista de Administração da UFSM, v. 4, p. 251-267, 2011.

TRIVIÑOS, A. N. Introdução à pesquisa em Ciências Sociais. São Paulo: Editora Atlas, 1987.

TSOUKAS, H. Postmodernism, reflexive rationalism and organizational studies. Organization Studies, v.13, n.4, p.643-650, 1992.

TURRA, F. R.; SANTOS, F. E. G.; COLTURATO, L. C. Associações e cooperativas. Serviço Nacional de Aprendizagem do Cooperativismo - Ed. Casa do Cooperativismo, Brasília, 2002.

VASCONCELLOS E.; HEMSLEY J. R. Estruturas das organizações: estruturas tradicionais, estruturas para inovação, estrutura matricial. 3. ed. São Paulo: Pioneira, 1997.

Verdú-Jover, J.A.; Lloréns-Montes, F. J.; GarcíaMorales, V. J. The concept of fit in services flexibility research: an empirical approach, International Journal of Service Industry Management, Vol. 15 Iss: 5, pp.499 - 514, 2004.

VOLBERDA, H. W. Toward the flexible form: how to remain vital in hypercompetitive environments. Organization Science, v. 7, n. 4, p. 359-374, 1996. Disponível em: <http://web.ebscohost.com/ehost/ detail ?vid=8\&sid=12152826-2358-4d1f-b16ba27f10809111\%40sessionmgr114\&hid=118\& bdata=Jmxhbmc9cHQtYnImc2I0ZT1laG9zdC1s $a X Z \mid \# d b=b t h \& A N=4436201>$. Acesso em 21 de jul. 2013.

Building the flexible firm: how to remain competitive. New York: Oxford University Press, 1998.

YIN, R. K. Case study research, design and methods. Thousand Oaks. California: Sage Publications, 2009. 